\title{
Post-Transplant Cyclophosphamide Combined with Anti-Thymocyte Globulin as Graft-versus-Host Disease Prophylaxis for Allogeneic Hematopoietic Cell Transplantation in High-Risk Acute Myeloid Leukemia and Myelodysplastic Syndrome
}

\author{
Wael Alanazi ${ }^{a}$ Shiyi Chen ${ }^{b}$ Jeffrey H. Lipton ${ }^{a}$ Dennis D. Kim ${ }^{a}$ \\ Auro Viswabandya ${ }^{a}$ Rajat Kumar ${ }^{a}$ Wilson Lam ${ }^{a}$ Arjun D. Law ${ }^{a}$ \\ Zeyad Al-Shaibani $^{\mathrm{a}}$ Jonas Mattsson ${ }^{\mathrm{a}}$ Fotios V. Michelis ${ }^{\mathrm{a}}$ \\ ${ }^{a}$ Hans Messner Allogeneic Transplant Program, Princess Margaret Cancer Centre, University Health Network, \\ University of Toronto, Toronto, ON, Canada; ${ }^{b}$ Department of Biostatistics, Princess Margaret Cancer Centre, \\ University Health Network, University of Toronto, Toronto, ON, Canada
}

\section{Keywords}

Allogeneic hematopoietic cell transplantation · Acute myeloid leukemia $\cdot$ Myelodysplastic syndrome $\cdot$ Antithymocyte globulin P Post-transplant cyclophosphamide

\begin{abstract}
Background: Allogeneic hematopoietic cell transplantation $(\mathrm{HCT})$ is curative for high-risk acute myeloid leukemia (AML) and myelodysplastic syndrome (MDS) but with significant non-relapse mortality (NRM) and relapse. We compared the combination of anti-thymocyte globulin (ATG; $4.5 \mathrm{mg} / \mathrm{kg}$ ) and post-transplant cyclophosphamide (PTCy; $50 \mathrm{mg} / \mathrm{kg}$ on day +3 and +4 ) with other graft-versus-host disease (GvHD) prophylaxis regimens used for these patients. Methods: We retrospectively analyzed 159 patients, aged 22-73 (median 56) years, having undergone transplantation for high-risk AML $(n=120)$ or MDS $(n=39)$. The donors were matched related (33\%), unrelated $(55 \%)$ and haploidentical (12\%). Almost all patients used peripheral blood stem cells. Conditioning was myeloablative (34\%) or reduced intensity (66\%). ATG + PTCy was used in 69 patients (43\%), and other GvHD
\end{abstract}

karger@karger.com

(c) 2020 S. Karger AG, Basel

www.karger.com/aha

Karger $\stackrel{2}{5}$ prophylaxis regimens in 90 patients (57\%). Results: Grade III-IV acute GvHD occurred in 4\% of the ATG + PTCy patients versus $20 \%$ of those using other regimens ( $p=0.004)$, and chronic GvHD in $19 \%$ of the ATG + PTCy patients versus $41 \%$ of those using other regimens $(p=0.003)$. Two-year GvHDfree relapse-free survival (GRFS) was 30\% with ATG + PTCy versus $18 \%$ with other regimens $(p=0.04)$. Multivariable analysis demonstrated that while ATG + PTCy had no significant influence on overall survival, cumulative incidence of relapse or NRM, there was a significant influence on GRFS in favor of ATG + PTCy (HR=0.69, 95\% Cl 0.45-0.99, $p=0.04)$. Conclusions: We conclude that the ATG + PTCy combination significantly improved GRFS in allogeneic HCT for high-risk AML and MDS without influencing other outcomes.

(c) 2020 S. Karger AG, Basel

\section{Introduction}

Allogeneic hematopoietic cell transplantation (HCT) remains a potentially curative option for myeloid malignancies such as acute myeloid leukemia (AML) and my- 
elodysplastic syndrome (MDS) [1, 2]. Allogeneic HCT, however, is also associated with the significant risk of non-relapse mortality (NRM) as well as post-transplant relapse, particularly for high-risk diseases such as AML with adverse cytogenetics [3] and high-risk MDS [4].

With regard to AML in particular, the European Leukemia Net (ELN) stratifies de novo AML into favorable, intermediate and adverse risk categories based on relapse risk [5]. Therapy-related AML demonstrates inferior outcomes without allogeneic HCT, with significantly lower overall survival (OS) and relapse-free survival rates than with de novo AML [6]. Even with allogeneic HCT, highrisk AML and MDS subtypes demonstrate a significantly higher incidence of relapse after transplantation, with a reported 3-year cumulative incidence of relapse (CIR) of 52 and 44\% for monosomal-karyotype AML and MDS, respectively [7]. Conditioning intensity plays a significant role in post-transplant relapse risk, with reduced-intensity regimens being associated with increased relapse rates. For high-risk myeloid malignancies, however, such as those with a monosomal karyotype, the relapse risk does not seem to be overcome by increasing the conditioning intensity $[7,8]$.

A significant reason for failure of allogeneic HCT is NRM related to acute and chronic graft-versus-host disease (GvHD). Many GvHD prophylaxis regimens have been developed over the years, and more recently the introduction of post-transplant cyclophosphamide (PTCy) has had a positive impact on outcomes $[9,10]$. Studies comparing haploidentical donor versus matched unrelated donor (MUD) transplantation for AML demonstrate a significant reduction in the rate of acute and chronic GvHD for haploidentical transplants, independent of conditioning intensity, without significant differences in OS and relapse rates compared to MUD transplants [11].

Anti-thymocyte globulin (ATG) as GvHD prophylaxis has proven to reduce the incidence of chronic GvHD without increasing relapse rates [12]. In a recent phase III multicenter trial, the addition of ATG for unrelated donor transplants demonstrated a cumulative incidence of acute GvHD at 100 days of $50 \%$ versus $65 \%$ for those without ATG, and the incidence of chronic GvHD was also lower in the ATG group (22 vs. 33\%) [13]. Because of the significant occurrence of acute GvHD that was observed even in the ATG group, we recently introduced a combination of ATG (total dose $4.5 \mathrm{mg} / \mathrm{kg}$ ) plus PTCy $(50 \mathrm{mg} / \mathrm{kg}$ on day +3 and +4$)$ as $\mathrm{GvHD}$ prophylaxis, which demonstrated an effective reduction of both severe acute and chronic GvHD and improved survival with
MUD transplants $[14,15]$. The favorable effect of this combination was also observed in the haploidentical donor setting [16], as well as for AML patients with varying disease risks using all types of allogeneic donor [17].

The challenge with allogeneic HCT for high-risk myeloid malignancies is the mitigation of potentially lethal GvHD without compromising the graft-versus-leukemia effect, which is required to achieve lasting disease control. The purpose of the present single-center study was to compare the combination of ATG + PTCy with other GvHD prophylaxis regimens in allogeneic HCT for highrisk AML and MDS performed at our center, and to determine the influence of the ATG + PTCy combination on relapse risk in this group of patients.

\section{Subjects and Methods}

\section{Study Cohort}

We retrospectively analyzed 159 patients, aged 22-73 years, that underwent allogeneic HCT at the Princess Margaret Cancer Centre, University Health Network, Toronto, ON, Canada, between January 2014 and July 2017 for high-risk disease (both AML and MDS). We defined high-risk AML as any of the following: AML secondary to MDS or other conditions [18], therapy-related AML [19], high-risk cytogenetics (ELN criteria) [5] and primary induction failure, which was defined as failure to achieve first complete remission (CR1) with 1 or more cycles of induction chemotherapy. All of the above high-risk patients underwent transplantation in CR1, as well as any patients who were transplanted in CR2 or more.

We defined high-risk MDS as secondary or therapy-related MDS [20] and de novo MDS with a high/very high WHO classification-based prognostic scoring system (WPSS) risk score. We used the WPSS as a dynamic prognostic scoring system that can be applied at different time points during the course of MDS evolution [21]. All MDS patients underwent transplantation if marrow blasts were no more than $10 \%$ at the pre-transplant assessment (either with or without prior cytoreductive treatment).

\section{Data}

Demographic data were collected from the Electronic Patient Record of our hospital as well as from the Allogeneic Blood and Marrow Transplant Program database. Data collected included patient age at HCT, graft source as bone marrow versus peripheral blood stem cells (PBSC), donor type (related or unrelated), cytomegalovirus serostatus and conditioning regimen intensity defined as myeloablative (MA) versus reduced-intensity conditioning (RIC). We documented the GvHD prophylaxis regimen used, including the combination of ATG with PTCy. We collected data starting from January 2014 up to and including July 2017; follow-up data were updated as of March 2019.

\section{Conditioning Regimens and GvHD Prophylaxis}

MA conditioning consisted of fludarabine at $30 \mathrm{mg} / \mathrm{m}^{2} /$ day for 4 days (day -5 to day -2 ), busulfan at $3.2 \mathrm{mg} / \mathrm{kg}$ (calculated by adjusted body weight)/day for 4 days (day -5 to day -2 ) and total 
body irradiation at $400 \mathrm{cGy}$ in 2 fractionated doses (on day -1), while the RIC regimen consisted of fludarabine at $30 \mathrm{mg} / \mathrm{m}^{2} /$ day for 4 days (day -5 to day -2 ), busulfan at $3.2 \mathrm{mg} / \mathrm{kg}$ (calculated by adjusted body weight)/day for 2 days (day -3 to day -2 ) and total body irradiation at $200 \mathrm{cGy}$ in 1 dose (on day -1).

We used dual T-lymphocyte suppression with ATG combined with PTCy as previously described [16]. For patients receiving the ATG + PTCy combination, the total dose of ATG was $4.5 \mathrm{mg} / \mathrm{kg}$ (administered on days -3 to -1 ) in combination with PTCy at 50 $\mathrm{mg} / \mathrm{kg}$ on days +3 and +4 , followed by cyclosporine A (CsA) started on day +5 . Of all patients, $69(43 \%)$ received the ATG + PTCy combination. Other GvHD prophylaxis regimens used included alemtuzumab combined with CsA in 42 patients (26\%), mycophenolate mofetil $(15 \mathrm{mg} / \mathrm{kg} \mathrm{q} 8 \mathrm{~h} \times 30$ days $)$ with CsA in 24 patients $(16 \%)$, methotrexate $\left(15 \mathrm{mg} / \mathrm{m}^{2}\right.$ on day +1 , and $10 \mathrm{mg} / \mathrm{m}^{2}$ on days $+3,+6$ and +11 ) with CsA in 18 patients $(11 \%)$, and a combination of ATG, methotrexate and CsA in $5(3 \%)$ patients, while 1 patient received ATG at $7.5 \mathrm{mg} / \mathrm{kg}$ from day -3 to day -1 (Table 1 ).

\section{Statistical Analysis}

The baseline patient characteristics are reported using descriptive statistics. The main outcome variables of interest included OS, CIR and cumulative incidence of NRM. The overall incidence of acute and chronic GvHD was documented, while GvHD-free relapse-free survival (GRFS) was calculated as previously described by Ruggeri et al. [22]. Univariate analyses of OS and GRFS were performed using the Kaplan-Meier product limit method, while CIR and NRM were determined using the cumulative incidence of competing events and Gray's test, with "death" as the competing event for CIR and "relapse" as the competing event for NRM. Multivariable analyses were performed using Cox proportional-hazards regression for OS and GRFS, whereas Fine and Gray proportional-hazards regression was used for CIR and NRM. The variables entered into the multivariable model underwent a stepwise selection algorithm with which variables with $p \geq 0.05$ were eliminated. The statistical analyses were performed using SAS version 9.4 (SAS Institute Inc., Cary, NC, USA).

\section{Results}

\section{Patient and Transplant Characteristics}

The baseline patient characteristics are summarized in Table 1 . The median age of the patients was 56 years (range 22-73). The patients underwent transplantation for high-risk AML $(n=120 ; 75 \%)$ or high-risk MDS ( $n=$ 39; 25\%). Among the AML patients, 39 were previously diagnosed with therapy-related/secondary AML in CR1, and 36 with high-risk cytogenetics or high-risk mutations in CR1; 13 were in CR1 following primary induction failure and 32 underwent transplantation in CR2 or more. As regards the MDS patients, 26 were previously diagnosed with high-/very-high-risk disease (WPSS) and 13 with secondary MDS.

The donors were matched related in 52 cases (33\%), HLA $10 / 10$ matched unrelated in 58 cases (36\%), HLA
Table 1. Baseline patient and transplant characteristics

\begin{tabular}{|c|c|}
\hline $\begin{array}{l}\text { Age at } H C T \\
<55 \text { years } \\
\geq 55 \text { years }\end{array}$ & $\begin{array}{l}71(45 \%) \\
88(55 \%)\end{array}$ \\
\hline $\begin{array}{l}\text { Transplant indication } \\
\text { AML } \\
\text { MDS }\end{array}$ & $\begin{array}{r}120(75 \%) \\
39(25 \%)\end{array}$ \\
\hline $\begin{array}{l}\text { Donor type } \\
\text { Matched related } \\
\text { HLA 10/10 unrelated } \\
\text { HLA 9/10 unrelated } \\
\text { Haploidentical }\end{array}$ & $\begin{array}{l}52(33 \%) \\
58(36 \%) \\
31(19 \%) \\
18(12 \%)\end{array}$ \\
\hline $\begin{array}{l}\text { Graft source } \\
\text { Peripheral blood stem cells } \\
\text { Bone marrow }\end{array}$ & $\begin{array}{r}158(99 \%) \\
1(<1 \%)\end{array}$ \\
\hline $\begin{array}{l}\text { Conditioning regimen } \\
\text { Myeloablative conditioning } \\
\text { Reduced-intensity conditioning }\end{array}$ & $\begin{array}{r}57(36 \%) \\
102(64 \%)\end{array}$ \\
\hline $\begin{array}{l}\text { GvHD prophylaxis } \\
\text { ATG + PTCy combination } \\
\text { Other prophylaxis regimens } \\
\text { Alemtuzumab + CsA } \\
\text { MMF + CsA } \\
\text { MTX + CsA } \\
\text { ATG + CsA + MTX } \\
\text { ATG } 7.5 \mathrm{mg} / \mathrm{kg}\end{array}$ & $\begin{array}{c}69(43 \%) \\
90(57 \%) \\
42(26 \%) \\
24(16 \%) \\
18(11 \%) \\
5(3 \%) \\
1(<1 \%)\end{array}$ \\
\hline $\begin{array}{l}\text { CMV serostatus } \\
\text { Both donor/recipient negative } \\
\text { Other combinations }\end{array}$ & $\begin{array}{r}18(11 \%) \\
141(89 \%)\end{array}$ \\
\hline $\begin{array}{l}\text { AML, acute myeloid leukemia } \\
\text { CMV, cytomegalovirus; CsA, cyc } \\
\text { hostdisease; HLA, humanleukocy } \\
\text { syndrome; MMF, mycophenola } \\
\text { PTCy, post-transplant cyclophos }\end{array}$ & $\begin{array}{l}\text {-thymocyte globulin; } \\
\text { GvHD, graft-versus- } \\
\text { ADS, myelodysplastic } \\
\text { MTX, methotrexate; }\end{array}$ \\
\hline
\end{tabular}

9/10 in 31 cases (19\%) and haploidentical in 18 cases (12\%). The graft source was PBSC for 158 patients (99\%). MA conditioning was used with 54 patients (34\%) and RIC regimens for 105 patients (66\%). PTCy combined with ATG was used in 69 patients (43\%) and other GvHD prophylaxis regimens were used in 90 patients (57\%). Both the donor and the recipient were cytomegalovirus seronegative in 18 cases $(11 \%)$.

\section{Univariate Analysis}

The median follow-up of the survivors was 29 months (range 14-56). Univariate analysis for the entire cohort demonstrated that the OS rate at 2 years was $49 \%$ (95\%
68

Acta Haematol 2021;144:66-73 DOI: $10.1159 / 000507536$
Alanazi et al. 
Table 2. Univariate analysis

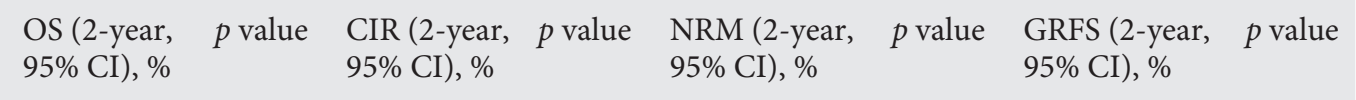

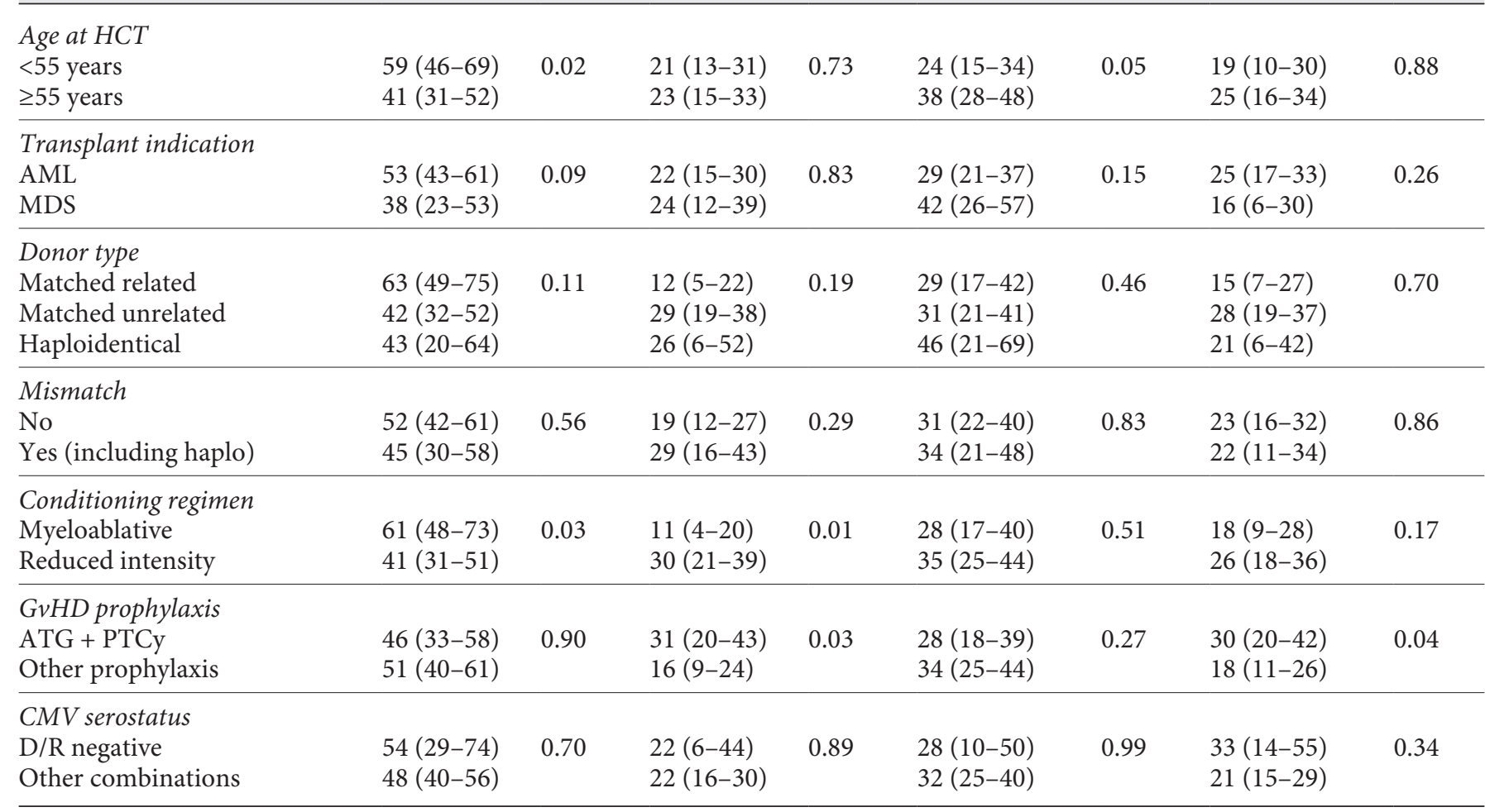

AML, acute myeloid leukemia; ATG, anti-thymocyte globulin; CI, confidence interval; CIR, cumulative incidence of relapse; CMV, cytomegalovirus; D/R, donor/recipient; GRFS, GvHD-free relapse-free survival; GvHD, graft-versus-host disease; MDS, myelodysplastic syndrome; NRM, non-relapse mortality; OS, overall survival; PTCy, post-transplant cyclophosphamide.

CI $41-57)$, CIR at 2 years was $22 \%$ (95\% CI 16-29) and NRM at 2 years was $32 \%$ (95\% CI 25-39).

For OS, significant variables were age at HCT (2-year OS $59 \%$ for age $<55$ years vs. $41 \%$ for age $\geq 55$ years; $p=$ 0.02 ) and conditioning regimen intensity ( 2 -year OS $61 \%$ with MA conditioning vs. $41 \%$ with RIC; $p=0.03$ ), while the use of the ATG + PTCy combination had no significant impact (2-year OS $46 \%$ with ATG + PTCy vs. $51 \%$ with other regimens; $p=0.90$ ) (Fig. 1; Table 2).

For CIR, conditioning regimen intensity $(11 \%$ at 2 years with MA conditioning vs. $30 \%$ with RIC; $p=0.01$ ) and GvHD prophylaxis ( $31 \%$ at 2 years with the ATG + PTCy combination vs. $16 \%$ for other regimens; $p=0.03$ ) (Fig. 2; Table 2) were the predominant variables, bearing in mind that all patients that received the ATG + PTCy combination (100\%) also received RIC, whereas only $37 \%$ of the patients that received other GvHD prophylaxis regimens underwent RIC. For NRM, age at HCT was border-

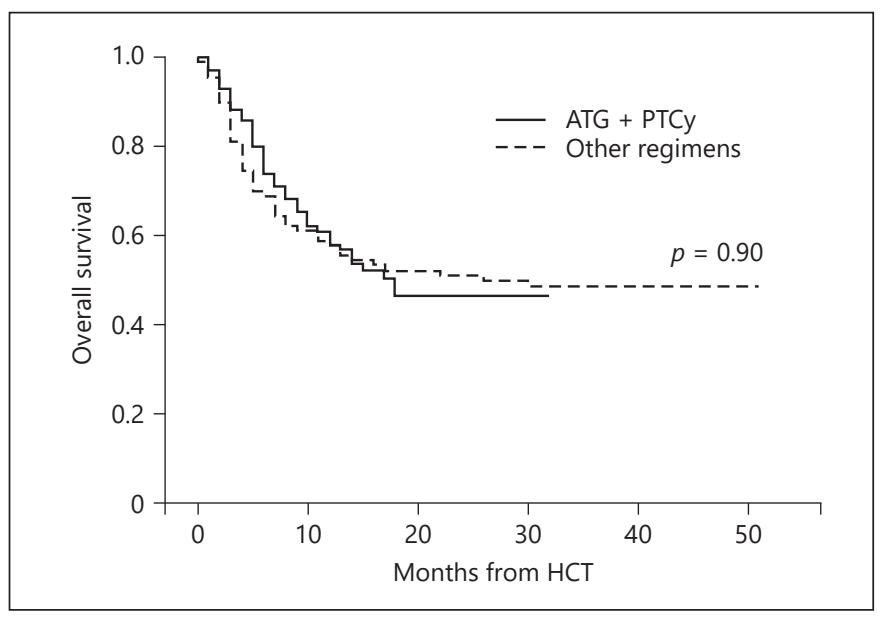

Fig. 1. Overall survival stratified by graft-versus-host disease prophylaxis regimen: anti-thymocyte globulin (ATG) + post-transplant cyclophosphamide (PTCy) versus other regimens. HCT, hematopoietic cell transplantation. 


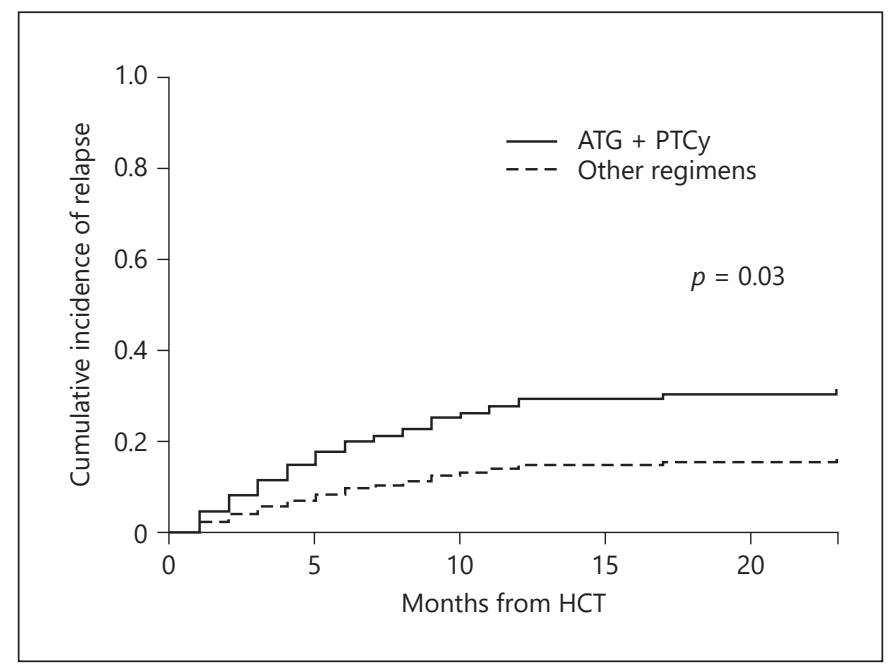

Fig. 2. Cumulative incidence of relapse stratified by graft-versushost disease prophylaxis regimen: anti-thymocyte globulin (ATG) + post-transplant cyclophosphamide (PTCy) versus other regimens. HCT, hematopoietic cell transplantation.

line significant (2-year NRM $24 \%$ for age $<55$ years vs. $38 \%$ for age $\geq 55$ years; $p=0.05$ ), while GvHD prophylaxis had no significant effect (2-year NRM 28\% with ATG + PTCy vs. $34 \%$ with other regimens; $p=0.27$ ) (Fig. 3; Table 2).

Grade II-IV acute GvHD was seen in 15/69 (23\%) of the ATG + PTCy patients versus 53/90 (59\%) of those using other regimens $(p<0.0001)$. Grade III-IV acute GvHD was seen in 3/69 (4\%) of the ATG + PTCy patients versus $18 / 90(20 \%)$ of those using other regimens $(p=$ 0.004 ). Moderate/severe chronic GvHD (requiring systemic treatment) was observed in $13 / 69(19 \%)$ of the ATG + PTCy patients versus 37/90 (41\%) of those using other regimens $(p=0.003)$. Among all the variables analyzed, univariate analysis for GRFS demonstrated borderline significance for the GvHD prophylaxis regimen (2year GRFS 30\% with ATG + PTCy vs. $18 \%$ with other regimens; $p=0.04$ ) (Fig. 4; Table 2).

\section{Multivariable Analysis}

Multivariable analysis (Table 3) for OS confirmed that the GvHD prophylaxis regimen had no influence $(p=$ $0.19)$, while the predominant predictor of survival was age at $\mathrm{HCT}(\mathrm{HR}=1.03,95 \% \mathrm{CI} 1.01-1.05, p=0.01)$. For CIR, the ATG + PTCy combination had no influence compared to other GvHD prophylaxis regimens $(p=0.6)$, while RIC was the predominant predictor of relapse $(\mathrm{HR}=3.05$ for RIC, 95\% CI 1.26-7.37, $p=0.01)$. For

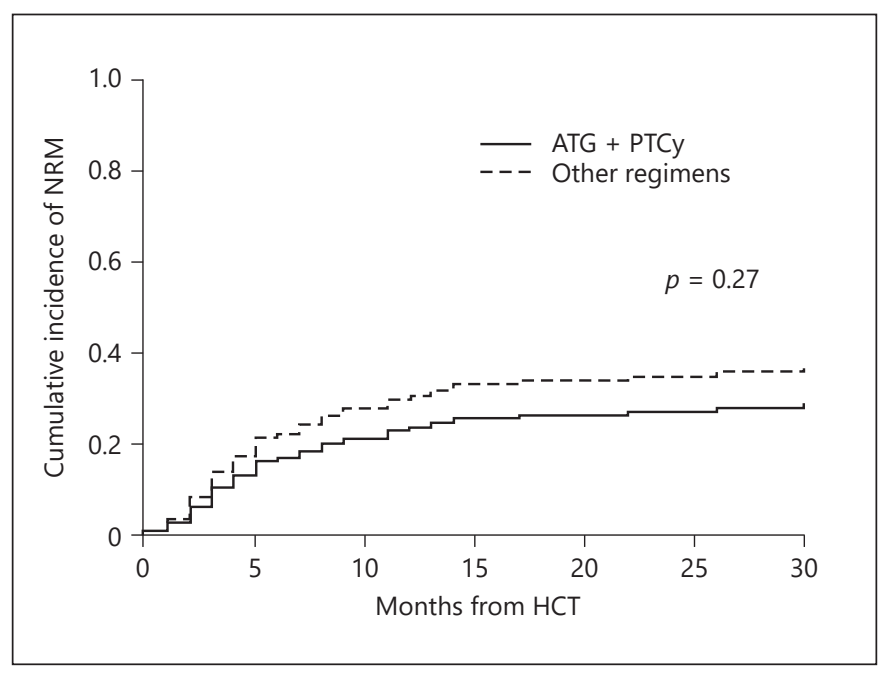

Fig. 3. Cumulative incidence of non-relapse mortality (NRM) stratified by graft-versus-host disease prophylaxis regimen: antithymocyte globulin (ATG) + post-transplant cyclophosphamide (PTCy) versus other regimens. HCT, hematopoietic cell transplantation.

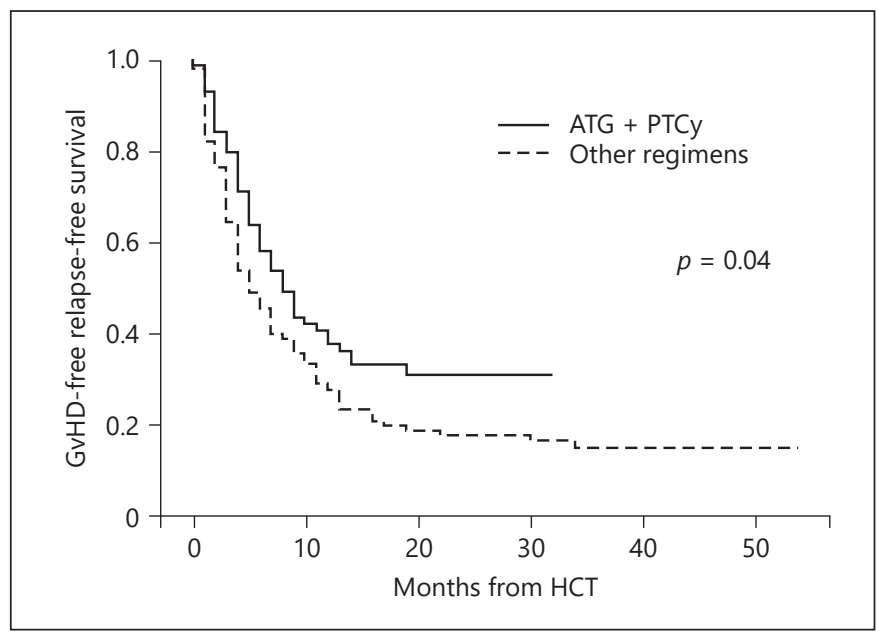

Fig. 4. Graft-versus-host disease (GvHD)-free relapse-free survival stratified by GvHD prophylaxis regimen: anti-thymocyte globulin (ATG) + post-transplant cyclophosphamide (PTCy) versus other regimens. HCT, hematopoietic cell transplantation.

NRM, the ATG + PTCy combination demonstrated no significant difference $(p=0.12)$, while age at HCT was the predominant predictor $(\mathrm{HR}=1.04,95 \%$ CI $1.01-1.07$, $p=0.02$ ). For GRFS, the predominant prognostic parameter was GvHD prophylaxis regimen, with the ATG + PTCy combination demonstrating a significantly lower HR $(\mathrm{HR}=0.69,95 \%$ CI $0.45-0.99, p=0.04)$. 
Table 3. Multivariable analysis

\begin{tabular}{lll}
\hline Parameter & HR (95\% CI) & $p$ value \\
\hline $\begin{array}{l}\text { Overall survival } \\
\text { Age at HCT }\end{array}$ & $1.03(1.01-1.05)$ & 0.01 \\
\hline $\begin{array}{l}\text { Cumulative incidence of relapse } \\
\begin{array}{l}\text { Conditioning regimen } \\
\text { (reduced intensity vs. myeloablative) }\end{array}\end{array}$ & $3.05(1.26-7.37)$ & 0.01 \\
\hline $\begin{array}{l}\text { Non-relapse mortality } \\
\text { Age at HCT }\end{array}$ & $1.04(1.01-1.07)$ & 0.02 \\
\hline $\begin{array}{l}\text { GvHD-free relapse-free survival } \\
\text { GvHD proph. group } \\
\text { (PTCy vs. others) }\end{array}$ & $0.69(0.45-0.99)$ & 0.04 \\
\hline
\end{tabular}

ATG, anti-thymocyte globulin; CI, confidence interval; GvHD, graft-versus-host disease; HCT, hematopoietic cell transplantation; HR, hazard ratio; proph., prophylaxis; PTCy, post-transplant cyclophosphamide.

\section{Cause of Death}

Of the 82 patients that died, 36 (44\%) had received the ATG + PTCy combination, among which 15 died of relapsed disease, 13 of various infectious complications, 2 of graft failure, 2 of GvHD and 4 of other causes. Of the other 46 patients $(56 \%)$ that had received other GvHD prophylaxis regimens, 16 died of GvHD, 12 died of relapse, 10 died of infectious complications, 4 died of graft failure and 4 died of other complications.

\section{Discussion}

In the present study, we demonstrated that for patients undergoing allogeneic HCT for high-risk myeloid malignancies, GvHD prophylaxis using the described ATG + PTCy combination was associated with a significant reduction in acute and chronic GvHD rates in comparison to other GvHD prophylaxis regimens used at our center. Survival rates and NRM were not negatively influenced by the use of the ATG + PTCy combination compared to other regimens, and while there was an observed increase in relapse on univariate analysis, this was not statistically significant on multivariable analysis. Regarding the incidence of GvHD within our own cohort, the effect of the GvHD prophylaxis regimen was profound: grade III-IV acute GvHD was seen in only $4 \%$ of the ATG + PTCy patients compared to $20 \%$ for other regimens, and for chronic GvHD, the difference was equally impressive in favor of ATG + PTCy. Importantly, the GRFS rate was

PTCy with ATG as GvHD Prophylaxis for

High-Risk AML and MDS actually superior for the ATG + PTCy group (2-year GRFS $30 \%$ vs. $18 \%$; Fig. 4; Tables 2, 3), thus demonstrating that the aforementioned GvHD prophylaxis regimen offers a higher percentage of GvHD-free and relapse-free patients despite the high risk of post-transplant relapse in this specific disease group.

As previously noted, all patients that received the ATG + PTCy combination also underwent RIC, which generally is considered to be associated with an increased relapse risk, at least in the non-high-risk disease groups [8]. However, various studies have demonstrated that while disease risk at diagnosis is a significant factor in predicting AML relapse after transplantation, conditioning intensity does not seem to play a role in the high-risk disease group [7, 8, 23].

During the study period, the described ATG + PTCy protocol was used for all donor types (fully matched related, MUD and haploidentical), while RIC regimens were used for patients of all ages because of concerns regarding organ toxicity when combining the MA conditioning regimen we use with PTCy, as described in previous studies [15]. During the development of the combined ATG + PTCy protocol, we hypothesized that this combination would decrease the incidence of grade IIIIV acute and moderate/severe chronic GvHD in a population predominantly transplanted using PBSC as a graft source, and this was demonstrated along with a significant survival advantage in numerous studies involving patients from our center [14-16].

Other studies have been performed to determine the influence of GvHD prophylaxis on post-transplant outcomes in myeloid malignancies. Park et al. [24] have shown that for MDS in particular, the use of RIC combined with ATG $\geq 7.5 \mathrm{mg} / \mathrm{kg}$ was associated with a favorable GRFS for patients with low-risk disease but not for high-risk patients including high-risk cytogenetics. The combination of PTCy with ATG has been described by Ruggeri et al. [25], who recently published a study involving 423 patients demonstrating that PTCy combined with other immunosuppressive drugs was associated with superior outcomes compared to PTCy alone, while 143 of those patients (34\%) had also received ATG. Use of ATG was associated with a decreased risk of severe chronic GvHD, although a subgroup analysis focusing on outcomes of the ATG + PTCy combination was not performed in that study. They did report a 2-year GRFS for PTCy alone of $24 \%$ [25], which we compare to $30 \%$ for our ATG + PTCy patients. We must stress that in other studies the favorable results of administering PTCy alone as GvHD prophylaxis in the unrelated donor setting were 
observed in transplants using bone marrow as a stem cell source $[26,27]$, while these results have not been confirmed if PBSC are used as a graft source [28], which is what we predominantly used at our center.

Another interesting observation regards the cause of death in our cohort when examined by GvHD prophylaxis regimen, where 16 patient deaths were attributable directly to GvHD when other prophylaxis regimens were used, compared to only 2 deaths attributable directly to GvHD among the ATG + PTCy patients. This observation, along with the fact that more patients survive concomitantly GvHD free and relapse free if the ATG + PTCy regimen is used, gives us an indirect idea on the potential of an improved quality of life for the ATG + PTCy patients, with less morbidity and a decreased hospitalization time, even if the difference in OS is not significant between the different GvHD prophylaxis groups.

We conclude with the present study that the ATG + PTCy combination for prophylaxis against acute and chronic GvHD may be administered to patients undergoing allogeneic HCT for high-risk AML or MDS without compromising survival or relapse rates. Moreover, this combination demonstrates a superior GRFS compared to other GvHD prophylaxis regimens previously used at our center, thus further demonstrating the potential of this combination for the improvement of post-allogeneic HCT outcomes. Further modifications of the combination, such as a decrease in the total dose of ATG or the administration of more intensive conditioning chemotherapy, may potentially improve survival by decreasing NRM and relapse rates, respectively.

\section{Statement of Ethics}

The study proposal was reviewed and approved by our institutional Research Ethics Board.

\section{Disclosure Statement}

The authors have no conflicts of interest to disclose.

\section{Author Contributions}

All authors contributed to the development, authorship and review of the research study and manuscript.

\section{References}

1 Koreth J, Schlenk R, Kopecky KJ, Honda S, Sierra J, Djulbegovic BJ, et al. Allogeneic stem cell transplantation for acute myeloid leukemia in first complete remission: systematic review and meta-analysis of prospective clinical trials. JAMA. 2009 Jun; 301(22):2349-61.

2 Platzbecker U. Treatment of MDS. Blood. 2019 Mar;133(10):1096-107.

3 Bejanyan N, Weisdorf DJ, Logan BR, Wang HL, Devine SM, de Lima M, et al. Survival of patients with acute myeloid leukemia relapsing after allogeneic hematopoietic cell transplantation: a center for international blood and marrow transplant research study. Biol Blood Marrow Transplant. 2015 Mar;21(3): 454-9.

4 de Witte T, Bowen D, Robin M, Malcovati L, Niederwieser D, Yakoub-Agha I, et al. Allogeneic hematopoietic stem cell transplantation for MDS and CMML: recommendations from an international expert panel. Blood. 2017 Mar;129(13):1753-62.

5 Döhner H, Estey E, Grimwade D, Amadori S, Appelbaum FR, Büchner T, et al. Diagnosis and management of AML in adults: 2017 ELN recommendations from an international expert panel. Blood. 2017 Jan;129(4):42447.

6 Kayser S, Döhner K, Krauter J, Köhne CH, Horst HA, Held G, et al.; German-Austrian AMLSG. The impact of therapy-related acute myeloid leukemia (AML) on outcome in 2853 adult patients with newly diagnosed AML. Blood. 2011 Feb;117(7): 2137-45.

7 Pasquini MC, Zhang MJ, Medeiros BC, Armand $\mathrm{P}, \mathrm{Hu} \mathrm{ZH}$, Nishihori T, et al. Hematopoietic Cell Transplantation Outcomes in Monosomal Karyotype Myeloid Malignancies. Biol Blood Marrow Transplant. 2016 Feb;22(2):248-57.

8 Solh MM, Solomon SR, Morris LE, Zhang X, Holland HK, Bashey A. The Dilemma of Conditioning Intensity: When Does Myeloablative Conditioning Improve Outcomes for Allogeneic Hematopoietic Cell Transplantation. Biol Blood Marrow Transplant. 2019 Mar;25(3):606-12.

9 Kasamon YL, Bolaños-Meade J, Prince GT, Tsai HL, McCurdy SR, Kanakry JA, et al. Outcomes of Nonmyeloablative HLA-Haploidentical Blood or Marrow Transplantation with High-Dose Post-Transplantation Cyclophosphamide in Older Adults. J Clin Oncol. 2015 Oct;33(28):3152-61.

10 Luznik L, O’Donnell PV, Symons HJ, Chen AR, Leffell MS, Zahurak M, et al. HLA-haploidentical bone marrow transplantation for hematologic malignancies using nonmyeloablative conditioning and high-dose, posttransplantation cyclophosphamide. Biol Blood Marrow Transplant. 2008 Jun;14(6): 641-50.
11 Ciurea SO, Zhang MJ, Bacigalupo AA, Bashey A, Appelbaum FR, Aljitawi OS, et al. Haploidentical transplant with posttransplant cyclophosphamide vs matched unrelated donor transplant for acute myeloid leukemia. Blood. 2015 Aug;126(8):1033-40.

12 Bacigalupo A, Lamparelli T, Barisione G, Bruzzi P, Guidi S, Alessandrino PE, et al.; Gruppo Italiano Trapianti Midollo Osseo (GITMO). Thymoglobulin prevents chronic graft-versus-host disease, chronic lung dysfunction, and late transplant-related mortality: long-term follow-up of a randomized trial in patients undergoing unrelated donor transplantation. Biol Blood Marrow Transplant. 2006 May;12(5):560-5.

13 Walker I, Panzarella T, Couban S, Couture F, Devins G, Elemary M, et al.; Canadian Blood and Marrow Transplant Group. Pretreatment with anti-thymocyte globulin versus no antithymocyte globulin in patients with haematological malignancies undergoing haemopoietic cell transplantation from unrelated donors: a randomised, controlled, open-label, phase 3, multicentre trial. Lancet Oncol. 2016 Feb;17(2):164-73.

14 Prem S, Atenafu EG, Al-Shaibani Z, Loach D Law A, Lam W, et al. Low rates of acute and chronic GVHD with ATG and PTCy in matched and mismatched unrelated donor peripheral blood stem cell transplants. Eur J Haematol. 2019 Jun;102(6):486-93. 
15 Deotare U, Atenafu EG, Loach D, Michelis FV, Kim DD, Thyagu S, et al. Reduction of severe acute graft-versus-host disease using a combination of pre transplant anti-thymocyte globulin and post-transplant cyclophosphamide in matched unrelated donor transplantation. Bone Marrow Transplant. 2018 Mar;53(3):361-5.

16 Law AD, Salas MQ, Lam W, Michelis FV, Thyagu S, Kim DD, et al. Reduced-Intensity Conditioning and Dual T Lymphocyte Suppression with Antithymocyte Globulin and Post-Transplant Cyclophosphamide as Graftversus-Host Disease Prophylaxis in Haploidentical Hematopoietic Stem Cell Transplants for Hematological Malignancies. Biol Blood Marrow Transplant. 2018 Nov;24(11): 2259-64.

17 Salas MQ, Prem S, Atenafu EG, Law AD, Lam $\mathrm{W}, \mathrm{Al}-$ Shaibani Z, et al. Reduced intensity allogeneic stem cell transplant with anti-thymocyte globulin and post-transplant cyclophosphamide in acute myeloid leukemia. Eur J Haematol. 2019 Nov; 103(5):510-8.

18 Nilsson C, Hulegårdh E, Garelius H, Möllgård L, Brune M, Wahlin A, et al. Secondary Acute Myeloid Leukemia and the Role of Allogeneic Stem Cell Transplantation in a PopulationBased Setting. Biol Blood Marrow Transplant. 2019 Sep;25(9):1770-8.

19 Ornstein MC, Mukherjee S, Mohan S, Elson P, Tiu RV, Saunthararajah Y, et al. Predictive Factors for Latency Period and a Prognostic Model for Survival in Patients with Therapyrelated Acute Myeloid Leukemia. Am J Hematol. 2014 Feb;89(2):168-73.
20 Ganser A, Heuser M. Therapy-related myeloid neoplasms. Curr Opin Hematol. 2017 Mar;24(2):152-8

21 Malcovati L, Germing U, Kuendgen A, Della Porta MG, Pascutto C, Invernizzi R, et al. Time-dependent prognostic scoring system for predicting survival and leukemic evolution in myelodysplastic syndromes. J Clin Oncol. 2007 Aug;25(23):3503-10.

22 Ruggeri A, Labopin M, Ciceri F, Mohty M, Nagler A. Definition of GvHD-free, relapsefree survival for registry-based studies: an ALWP-EBMT analysis on patients with AML in remission. Bone Marrow Transplant. 2016 Apr;51(4):610-1.

23 Shimoni A, Labopin M, Savani B, Byrne M, Volin L, Finke J, et al. Comparable LongTerm Outcome after Allogeneic Stem Cell Transplantation from Sibling and Matched Unrelated Donors in Patients with Acute Myeloid Leukemia Older Than 50 Years: A Report on Behalf of the Acute Leukemia Working Party of the European Society for Blood and Marrow Transplantation. Biol Blood Marrow Transplant. 2019 Nov;25(11):225160.

24 Park SS, Jeon YW, Min GJ, Park S, Yahng SA, Yoon JH, et al. Graft-versus-Host DiseaseFree, Relapse-Free Survival after Allogeneic Stem Cell Transplantation for Myelodysplastic Syndrome. Biol Blood Marrow Transplant. 2019 Jan;25(1):63-72.
25 Ruggeri A, Labopin M, Bacigalupo A, Afanasyev B, Cornelissen JJ, Elmaagacli A, et al. Post-transplant cyclophosphamide for graftversus-host disease prophylaxis in HLA matched sibling or matched unrelated donor transplant for patients with acute leukemia, on behalf of ALWP-EBMT. J Hematol Oncol. 2018 Mar;11(1):40.

26 Kanakry CG, O’Donnell PV, Furlong T, de Lima MJ, Wei W, Medeot M, et al. Multi-institutional study of post-transplantation cyclophosphamide as single-agent graft-versushost disease prophylaxis after allogeneic bone marrow transplantation using myeloablative busulfan and fludarabine conditioning. J Clin Oncol. 2014 Nov;32(31):3497-505.

27 Luznik L, Bolaños-Meade J, Zahurak M, Chen AR, Smith BD, Brodsky R, et al. Highdose cyclophosphamide as single-agent, short-course prophylaxis of graft-versushost disease. Blood. 2010 Apr;115(16):322430.

28 Bradstock KF, Bilmon I, Kwan J, Micklethwaite K, Blyth E, Deren S, et al. SingleAgent High-Dose Cyclophosphamide for Graft-versus-Host Disease Prophylaxis in Human Leukocyte Antigen-Matched Reduced-Intensity Peripheral Blood Stem Cell Transplantation Results in an Unacceptably High Rate of Severe Acute Graft-versus-Host Disease. Biol Blood Marrow Transplant. 2015 May;21(5):941-4. 